\title{
MORFOANATOMIA E HISTOQUÍMICA DOS ÓRGÃOS VEGETATIVOS DE Boerhavia diffusa L. (NYCTAGINACEAE)
}

\section{Leticia Elias $^{1}$, Elisa Mitsuko Aoyama}

${ }^{1}$ Departamento de Ciências Agrárias e Biológicas, Centro Universitário Norte do Espírito Santo, Universidade Federal do Espírito Santo Rodovia BR 101 Norte km 60, Litorâneo, São Mateus, ES, Brasil, CEP 29932-540.

Email: leticia_dominicini@hotmail.com

Recebido em: 22/09/2018 - Aprovado em: 23/11/2018 - Publicado em: 03/12/2018 DOI: 10.18677/EnciBio_2018B61

\begin{abstract}
RESUMO
Boerhavia diffusa L., mais conhecida como erva-tostão, é uma planta herbácea nativa da América Tropical, ocorrente no Brasil, com usos na medicina popular. Devido aos trabalhos escassos no país, além de usos errôneos causados pela má identificação das plantas. O trabalho objetiva-se em descrever a morfoanatomia dos órgãos vegetativos de $B$. difusa atrelado a testes histoquímicos, para contribuir na correta identificação da espécie além de fornecer subsídios para estudos farmacológicos. Para a descrição morfológica foram avaliados habitat da planta, padrão de ramificação, divisão do limbo, forma, filotaxia, consistência, superfície, venação, tipo de ápice, base e margem. As análises anatômicas foram realizadas segundo técnicas usuais de anatomia vegetal. Para os testes histoquímicos foram testadas as seguintes substâncias: amido, compostos fenólicos, cristais, látex, lignina, lipídeo e proteína. $B$. diffusa apresenta raíz tuberosa, caule aéreo rastejante do tipo prostrado e folhas simples. Anatomicamente, idioblastos com cristais de ráfides foram observados em todos os órgãos vegetativos. Pode-se concluir que raízes e caules apresentam padrão de crescimento anômalo, característica comum para a ordem Caryophyllales. O formato cordiforme e a base cordada da folha são caracteres distintivos entre as demais espécies do gênero. A parede celular sinuosa das células epidérmicas e presença da bainha do feixe são caracteres anatômicos foliares que juntamente com os caracteres morfológicos auxiliam na identificação da espécie. Os testes histoquímicos destacaram a presença de amido, lignina e lipídeo, que além de servir como fonte energética no caso do amido, são substâncias que podem auxiliar à resistência do vegetal no ambiente.
\end{abstract}

PALAVRAS- CHAVE: Caracterização Anatômica, Caryophyllales, Medicina Popular, Testes Histoquímicos.

\section{MORPHOANATOMY AND HISTOCHEMISTRY OF THE VEGETATIVE ORGANS OF Boerhavia diffusa L. (NYCTAGINACEAE)}

\begin{abstract}
Boerhavia diffusa L., better known as "erva-tortão", is an herbaceous plant native to tropical America, occurring in Brazil, with uses in traditional medicine. Due to the scarce work in the country, in addition to erroneous uses caused by poor identification of plants. This work aims to describe the morphoanatomy of the vegetative organs of $B$. diffusa attached to histochemical tests, to contribute to the
\end{abstract}


correct identification of the species besides provide subsidies for pharmacological studies. For the morphological description were evaluated plant habitat, branching pattern, limb division, shape, phyllotaxis, consistency, surface, venation, apex type, base and margin. The anatomical analyzes were performed according to usual techniques of plant anatomy. For the histochemical tests the following substances were tested: starch, phenolic compounds, crystals, latex, lignin, lipid and protein. $B$. diffusa presents tuberous root, aerial trailing stem of prostrate type and simple leaves. Anatomically, idioblasts with raphide crystals were observed in all vegetative organs. It can be concluded that roots and stems present anomalous growth pattern, common characteristic for the order Caryophyllales. The cordiform format and the cordate base of the leaf are distinctive characters between the other species of the genus. The sinuous cell wall of the epidermal cells and presence of the sheath of the bundle are anatomical foliar characters that along with the morphological characters help in the identification of the species. Histochemical tests highlighted the presence of starch, lignin and lipid, which besides serving as an energy source in the case of starch, are substances that can aid the resistance of the vegetable in the environment.

KEYWORDS: Anatomical Characterization, Caryophyllales, Traditional Medicine, Histochemical Tests.

\section{INTRODUÇÃO}

O uso de plantas na medicina tradicional é tão antigo quanto as próprias civilizações, configurando-se como um dos métodos terapêuticos mais primitivos. A prática curativa e o conjunto de saberes atrelado às espécies vegetais são passados de geração em geração (BRANDELLI, 2017).

As plantas medicinais são definidas como qualquer espécie vegetal, cultivadas ou não, com presença em um ou mais órgãos, de substâncias com potencialidades farmacológicas (BRANDELLI, 2017). No que tange ao aspecto social, as plantas medicinais são muito utilizadas em tratamentos para fins terapêuticos devido ao fácil acesso e baixo custo, sendo uma maneira alternativa aos fármacos industrializados tão difundidos atualmente (ZENI et al., 2017).

Entretanto, essa prática torna-se um problema quando a população passa a fazer uso de plantas que possuem muitas sinonímeas ou regionalidades (SILVA et al., 2010), sem estudos científicos para comprovação dos seus benefícios. Com isso, muitas delas são utilizadas de forma errônea, devido ao fato da parte consumida nem sempre corresponder a qual pertence o composto.

A erva-tostão pertence a família Nyctaginaceae e constitui o nome popular de algumas espécies do gênero Boerhavia L. Estudos sobre a morfoanatomia da planta, bem como a localização dos seus compostos são importantes para evitar intoxicações. Boerhavia diffusa L., é uma planta herbácea, nativa da América Tropical, ocorrente no Brasil. Planta ruderal que se alastra pelo chão, levantando seus ramos até aproximadamente $70 \mathrm{~cm}$ de comprimento (GRANDI, 2014). Comumente considerada como daninha, apresenta raíz dilatada pelo acúmulo de substâncias nutritivas, além de possuir flores e frutos pequenos, cujos frutos se aderem a pele (LORENZI; MATOS, 2008).

Devido a compostos químicos como flavonóides, alcalóides, lipídios e proteínas (MISHRA et al., 2014), B. Diffusa possui utilização na medicina popular por suas atividades imunossupressoras, hepatoprotetota, antibacteriana e antioxidante (WAJID et al., 2017). Além disso, suas partes são comumente utilizadas no 
tratamento de inflamações, icterícia, dores abdominais, problemas de pele, doenças oculares e infecções (MISHRA et al., 2014). Ainda segundo os autores, o suco de suas folhas possui propriedades analgésicas.

No Brasil, a planta possui usos para males do baço, virtudes peitorais e atualmente vem sendo utilizada contra a malária (GRANDI, 2014). Messias et al. (2015), em pesquisa com moradores de uma área urbana em Ouro Preto/MG, mostraram que raiz da erva tostão pode ser preparada como macerado ou utilizada in natura para tratamentos de males do fígado, no auxílio da digestão, para manchas na pele, antigripal e diurético.

Algumas plantas possuem similaridades com B. diffusa e nesse contexto, alguns trabalhos foram desenvolvidos buscando separá-la de outras espécies do gênero (BABU et al., 2017; VADIVEL; BRINDHA, 2017) ou até mesmo de outras espécies da ordem Caryophyllales (PATIL et al., 2016) devido às suas semelhanças e consequentemente pelos usos indevidos.

Pelo fato da espécie não ser bem estudada no Brasil, além do fato das plantas medicinais serem utilizadas erroneamente devido à má identificação das espécies, são necessários estudos morfoanatômicos e histoquímicos para a observação dos compostos presentes em $B$. difusa, bem como sua localização, para avaliar se todos os órgãos, principalmente raíz, parte da planta utilizada pela população, possuem esses compostos, e em que intensidade.

Dessa forma, o objetivo do trabalho foi descrever a morfologia e anatomia estrutural dos órgãos vegetativos de $B$. difusa, atrelado a testes histoquímicos, a fim de contribuir na correta identificação da espécie, além de fornecer subsídios para estudos farmacológicos e de atividade biológica.

\section{MATERIAL E MÉTODOS}

A espécie vegetal (figura $1 \mathrm{~A}$ ) foi coletada na Universidade Federal do Espirito Santo, Campus São Mateus (S 1840'31" W 3951'49") e incluída ao acervo do herbário SAMES, pertencente à mesma Universidade, sob o número 7947.

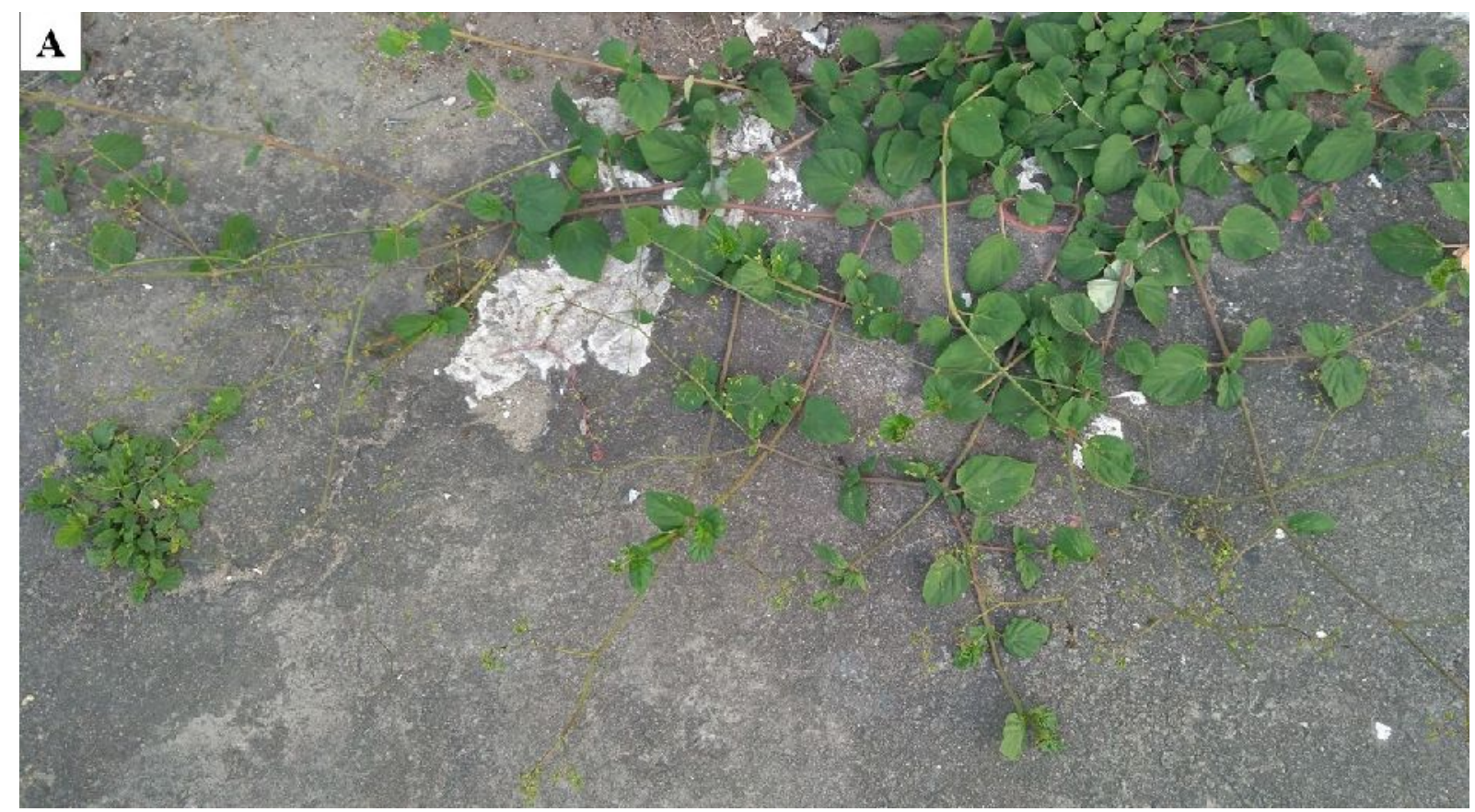

FIGURA 1. Aspectos gerais de Boerhavia diffusa L. Fonte: Leticia Elias. 


\section{Descrição Morfológica}

A análise morfológica de raíz foi realizada com base no habitat da planta, e para a descrição de caule, os caracteres analisados foram habitat e padrão de ramificação, segundo às terminologias de Bell (2008).

Para o estudo morfológico foram analisados caracteres foliares relacionados à divisão do limbo, forma, filotaxia, consistência, superfície, venação, tipo de ápice, base e margem, segundo terminologias de Ellis et al. (2009).

\section{Análises Anatômicas}

Os indivíduos foram fixados em FAA 50 (formaldeído: ácido acético: álcool etílico 50\%, 2:1: $18 \mathrm{v} / \mathrm{v}$ ), de acordo com Johansen (1940), por 48 horas e posteriormente transferidos para álcool $70 \%$.

Foram selecionadas folhas totalmente expandidas, retiradas do $3^{\circ}$ ao $6^{\circ}$ nó. Secções transversais foram obtidas da região mediana de raíz, colo, caule e folha e secções paradérmicas das faces adaxial e abaxial para visualização dos estômatos. O material seccionado foi clarificado em hipoclorito de sódio $25 \%$, corado com azul de alcian $0,5 \%$ e safranina $1 \%$ (LUQUE et al., 1996) e posteriormente montadas lâminas temporárias. As lâminas foram analisadas ao microscópio óptico e as imagens obtidas em fotomicroscópio com projeção de escalas micrométricas.

\section{Testes Histoquímicos}

Secções transversais não clarificadas dos órgãos vegetativos foram tratadas com: solução de Lugol para amido (JOHANSEN, 1940); Ácido acético concentrado e Ácido sulfúrico $10 \%$ para verificação de composição química em cristais (MILLER, 1968); Sudan IV em etanol para lipídeos totais (PEARSE, 1972); Solução aquosa de Cloreto Férrico III para marcação de compostos fenólicos (JOHANSEN, 1940); Sudan IV em acetona e etanol 70\% para marcação de látex (MILLER, 1968); Solução de floroglucina ácida para lignina (JOHANSEN, 1940) e Solução aquosa de hidróxido de potássio $0,2 \%$ + sulfato de cobre $10 \%$ + solução aquosa de hidróxido de potássio $2 \%$ para marcação de proteínas (PURVIS et al., 1964).

\section{Descrição Morfológica}

\section{RESULTADOS E DISCUSSÃO}

$B$. diffusa é uma planta herbácea, apresenta raiz axial tuberosa (figura $2 A$ ), dilatada pelo acúmulo de reservas nutritivas. O caule é aéreo rastejante, do tipo prostrado, cilíndrico, com coloração avermelhada na face adaxial e verde na face abaxial (figura 2C) e padrão de ramificação em dicásio (figura 2B). Possui folha simples, incompleta, com anisofilia (figura 2D), peciolada, filotaxia oposta cruzada, superfícies rugosas, venação do tipo broquidódroma (figura 2D), consistência herbácea, forma cordiforme (figura 2D), bordo piloso com ligeiras ondulações (figuras 2C, 2E), ápice obtuso (figura 2D), base cordada (figura 2D) e faces com diferentes colorações, sendo verde escuro na face adaxial e verde claro na abaxial (figura 2E). As flores são pequenas, de coloração arroxeada e os frutos são verdes, glandulares e viscosos (figura $2 \mathrm{~F}$ ), de fácil aderência a pele e tecidos. 

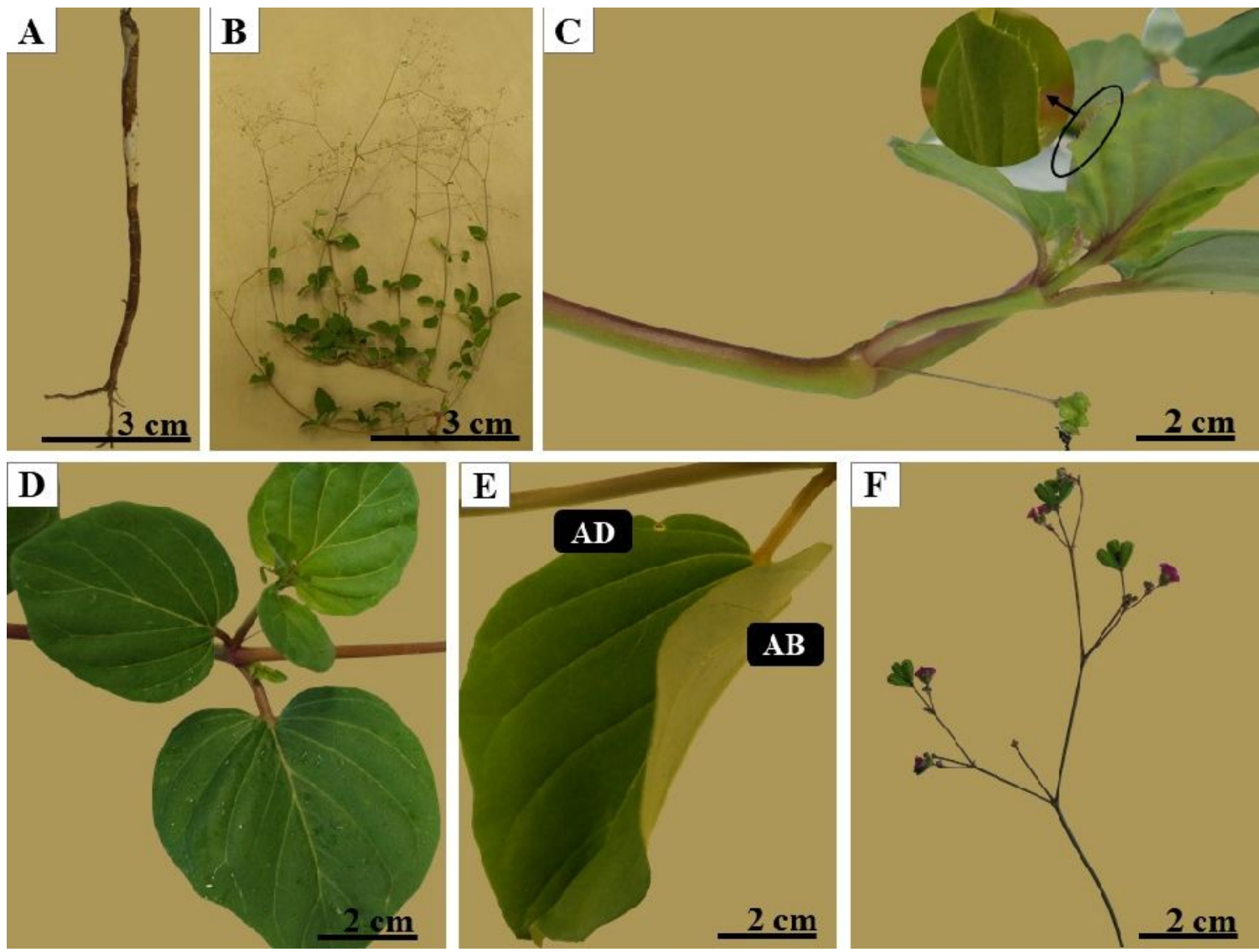

FIGURA 2. Boerhavia diffusa. A. Raíz tuberosa. B. Padrão de ramificação em dicásio. C. Caule com dupla coloração e folhas com bordo piloso (em detalhe). D. Disposição das folhas no caule evidenciando a anisofilia, tipo de nervação, forma, ápice e base foliar. $\mathbf{E}$. Detalhe da folha mostrando as diferentes colorações em ambas as faces; verde escuro (adaxial) e verde claro (abaxial). F. Detalhe do escapo onde estão inseridas as flores (rosas) e frutos (verdes). Fonte: Leticia Elias.

Nandi e Ghosh (2016) descrevem a folha de B. diffusa como ovada a oblonga, e Pramanick e Maiti (2017) a descrevem como ovada a lanceolada, entretanto, nenhum dos formatos foi observado para a espécie, mostrando que as diferentes condições ambientais podem interferir na morfologia do órgão. Devido às condições adversas, as plantas podem expressar mecanismos estruturais adaptativos que possibilitam sua permanência em ambientes extremos (WAECHTER, 1985).

Dependendo das condições ambientais em que as plantas se encontram, elas podem alterar sua morfologia ou fisiologia. Dentre os órgãos vegetativos, a folha é altamente plástica, possuindo maior capacidade de adaptação, comumente devido à exposição aos fatores ambientais adversos (GUERRA; SCREMIN-DIAS, 2017).

\section{Caracterização Anatômica}

Em vista transversal, a anatomia radicular apresenta crescimento secundário, evidenciado pela periderme (figura 3B). O córtex é parenquimático, com presença de grãos de amido e feixes de ráfides espalhados por toda extensão do parênquima (figura 3B). O amido é formado durante a fotossíntese, resultante da polimerização de glicose e, apesar de ser encontrado com facilidade nos vegetais, poucas são as plantas utilizadas para sua obtenção (OLIVEIRA; AKISSUE, 2009).

Ainda segundo os autores, além de corresponder a principal fonte de reserva das plantas, o amido também possui importante papel na alimentação humana e dos 
animais. Loehle (1995) observou ainda que plantas cujas raízes armazenam amido são mais propensas ao rebrotamento mesmo após o corte. A espécie possui alta capacidade de rebrota, podendo esta ser uma explicação para a sua conquista em muitos ambientes, chegando a ser considerada como daninha.

Os elementos vasculares apresentam padrão de crescimento anômalo com vários cordões de xilema e floema (figuras $3 \mathrm{~A}, 3 \mathrm{C}$ ). A região da medula é preenchida por xilema (figura $3 \mathrm{~A}$ ), onde foi observada a presença de lignina por meio dos testes histoquímicos (tabela 1).
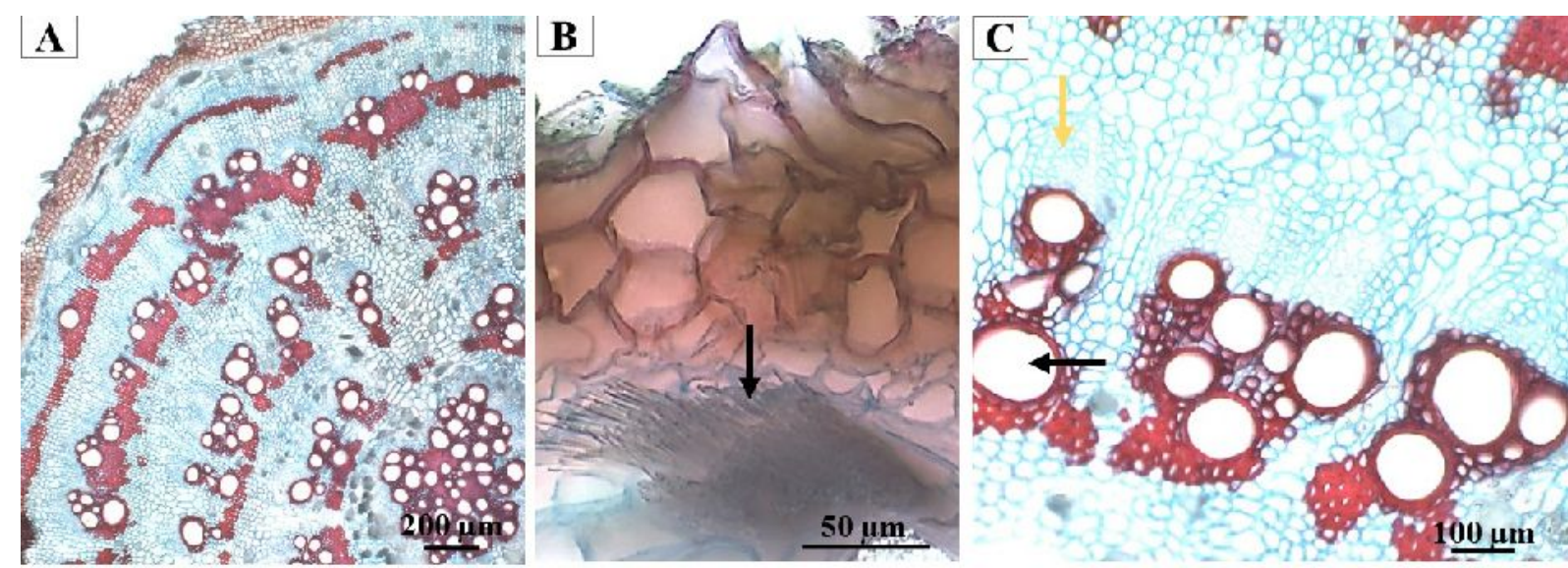

FIGURA 3. Secções transversais da raíz de Boerhavia diffusa. A. Vista Geral evidenciando o crescimento anômalo. B. Detalhe da periderme e de cristais do tipo ráfides (seta). C. Detalhe dos elementos vasculares radiculares (seta amarela: Floema; seta preta: Metaxilema). Fonte: Leticia Elias.

TABELA 1. Testes histoquímicos e intensidade da marcação nos órgãos vegetativos de $B$. diffusa.

\begin{tabular}{cl}
\hline $\begin{array}{c}\text { Substâncias Amido Cristais } \\
\begin{array}{c}\text { Partes do } \\
\text { vegetal }\end{array}\end{array}$ & $\begin{array}{l}\text { Compostos Látex Lignina Lipídeo Proteína } \\
\text { Fenólicos }\end{array}$ \\
\hline
\end{tabular}

\begin{tabular}{cccccccc}
\hline Raiz & & & & & & & - \\
Córtex & ++ & ++ & - & - & ++ & - & - \\
Cilindro & - & - & - & - & ++ & - & - \\
Vascular & - & - & - & - & ++ & - & - \\
Medula & - & - & - & & & & - \\
Caule & & - & - & - & - & ++ & - \\
Cutícula & - & - & - & - & ++ & - & - \\
Córtex & + & + & - & - & ++ & & - \\
Cilindro & - & - & - & & & & \\
Vascular & & & - & - & - & + & - \\
Folha & - & - & - & - & - & - & - \\
Cutícula & - & ++ & - & - & - & - & - \\
Mesofilo & - & - & - & - & - & - \\
Bainha do & ++ & - & - & - & + & - & - \\
feixe & Xilema & - & - & - & -
\end{tabular}

${ }^{*}$ Reação negativa (-) Moderadamente positiva (+) Fortemente positiva (++)

A lignina é um componente estrutural da lamela média e parede celular das plantas, com funcionalidade no transporte de água, nutrientes e metabólitos (SALIBA 
et al., 2001). Além disso, é encontrada na parede celular dos tecidos condutores e de sustentação, conferindo resistência mecânica aos vegetais, protegendo os tecidos contra o ataque de microrganismos (OLIVEIRA; AKISSUE, 2009).

O colo que é uma região de transição entre a raíz e o caule, possui anatomia de ambos os órgãos (figura 4A). Em trechos, a região é preenchida por periderme e subsequente, córtex parenquimático com feixes de ráfides (figura 4D) e elementos vasculares formando vários cordões de xilema e floema (figura 4B). Em conexão com a periderme, encontram-se trechos preenchidos por epiderme, com presença de tricomas e estômatos. A região cortical é parenquimática, onde estão dispersos feixes de ráfides (figura 4D) e posteriormente, os feixes vasculares (figura 4C), que formam um cordão contínuo com os feixes vasculares radiculares. A região central é preenchida com feixes vasculares colaterais dispersos de forma aleatória (figura 4E).

Embora Rajput e Rao (1998) observarem o padrão de crescimento anômalo para a espécie, os autores descrevem a anatomia caulinar com espessamento secundário. Patil et al. (2016) também encontraram o mesmo padrão caulinar para $B$. diffusa observado pelos autores acima. Contudo, no presente trabalho, foram seccionadas várias regiões do caule e a única que apresentou anatomia similar foi a região do colo (figura $4 \mathrm{~A}$ ). Quando seccionado $2 \mathrm{~cm}$ acima do colo e ao longo do caule, a anatomia caulinar se mostrou diferente do observado para essa região de transição, não corroborando com o achado dos autores.

Esse resultado mostra que a variação ambiental pode estar interferindo na anatomia estrutural da espécie, devido aos trabalhos anteriores terem sido realizados na Índia e o presente estudo, no Brasil. De acordo com Baas (1973), os fatores climáticos e ambientais detêm grande influência sobre os aspectos morfológicos e anatômicos nas plantas.
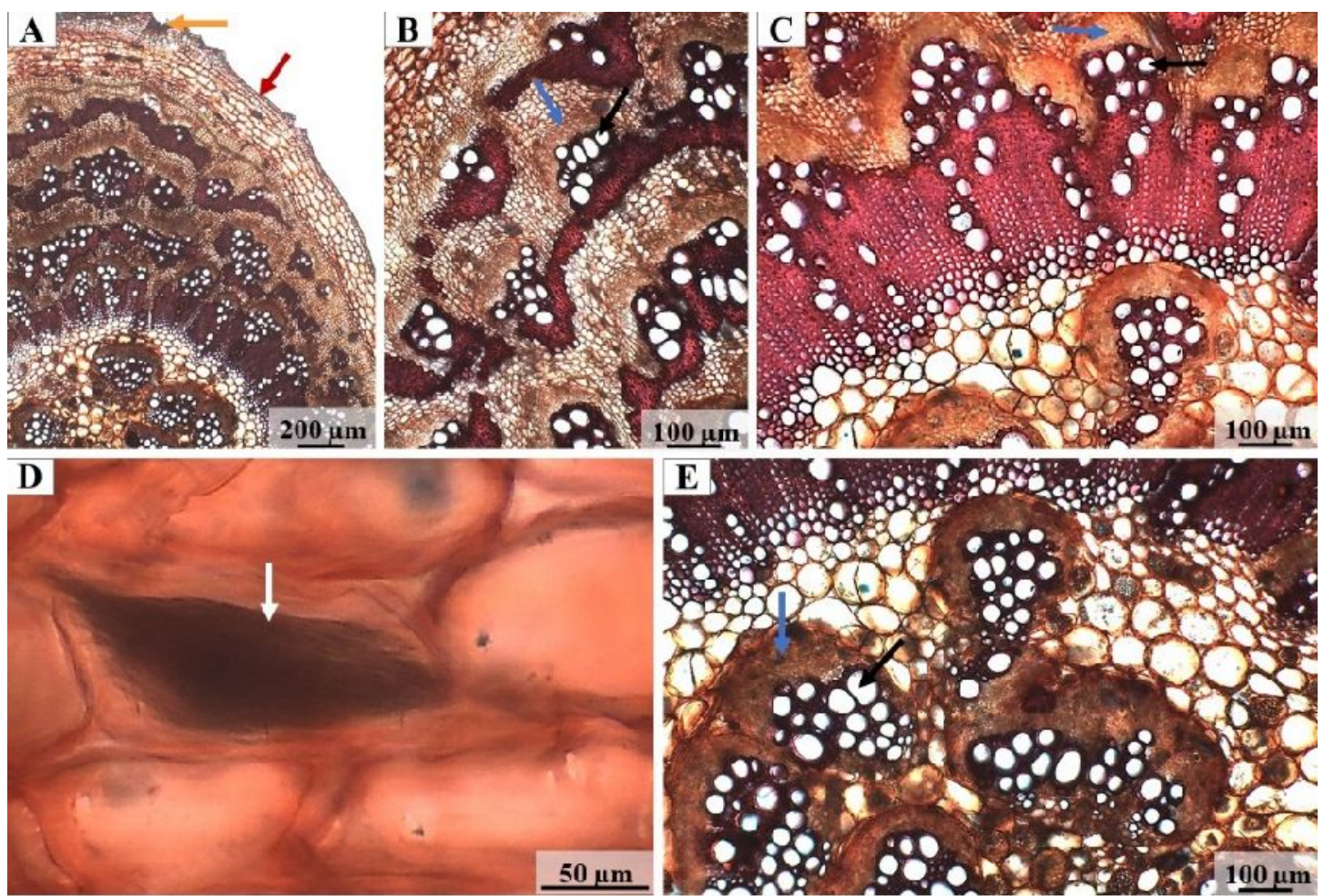

FIGURA 4. Secções transversais do colo. A. Região de transição entre raíz e caule (seta amarela: evidencia o crescimento secundário; seta vermelha: mostra o crescimento primário. B. Detalhe dos feixes vasculares radiculares. C. Detalhe dos feixes vasculares caulinares. D. Idioblastos com cristais do tipo ráfides presentes na região cortical (seta). E. Feixes vasculares colaterais presentes na medula. Setas azuis: Floema; setas pretas: Metaxilema. Fonte: Leticia Elias. 
O caule também possui padrão de crescimento anômalo. O órgão apresenta transição entre crescimento primário e secundário, e mesmo com o crecimento secundário formado, externamente, não chega a formar periderme. Em secção transversal exibe epiderme uniestratificada com presença de estômatos, sendo as células isodiamétricas recobertas por cutícula delgada (figura 5B). De acordo com Figueiredo et al. (2007) a cutícula é uma estrutura rica em compostos lipídicos e seus derivados, sendo as reservas lipídicas comumente encontradas sob a forma de gotículas dispersas no citoplasma.

Em posição subepidérmica ocorre uma bainha constituida por 1 a 3 camadas de colênquima angular, não formando um cilindro contínuo, devido a interrupção nas câmaras subestomáticas (figura 5B). Na região cortical também estão presentes idioblastos com cristais de oxalato de cálcio do tipo ráfides, as células do parênquima clorofiliano possuem formato oval com espaços intecelulares e a camada mais interna do córtex é constituída pela bainha amilífera (figura 5B).

Patil et al. (2016) relataram a presença de idioblastos com cristais de ráfides no caule e na folha da planta, mostrando que esse caractér é comum para $B$. diffusa, bem como para outras espécies do gênero (STRUWIG et al., 2011). Dentre as inclusões inorgânicas citoplasmáticas, as de oxalato de cálcio são as mais comuns e provém da combinação do ácido oxálico resultante do metabolismo vegetal com os sais de cálcio extraídos do solo pela planta (OLIVEIRA; AKISSUE, 2009). Os autores ainda citam que a forma dos cristais, sua localização e a presença em determinados órgãos são importantes no reconhecimento de espécies bem como na diagnose de drogas vegetais.

Cordões com pequenos feixes vasculares intercalados por parênquima fundamental (figura 5A) circundam o órgão e a presença do câmbio dando origem a floema e xilema secundários, evidenciando a transição para crescimento secundário (figura 5B). Na região central do órgão, as células são providas de espaços intercelulares e existem feixes medulares colaterais dispersos de forma aleatória (figuras $5 \mathrm{~A}, 5 \mathrm{C}$ ).
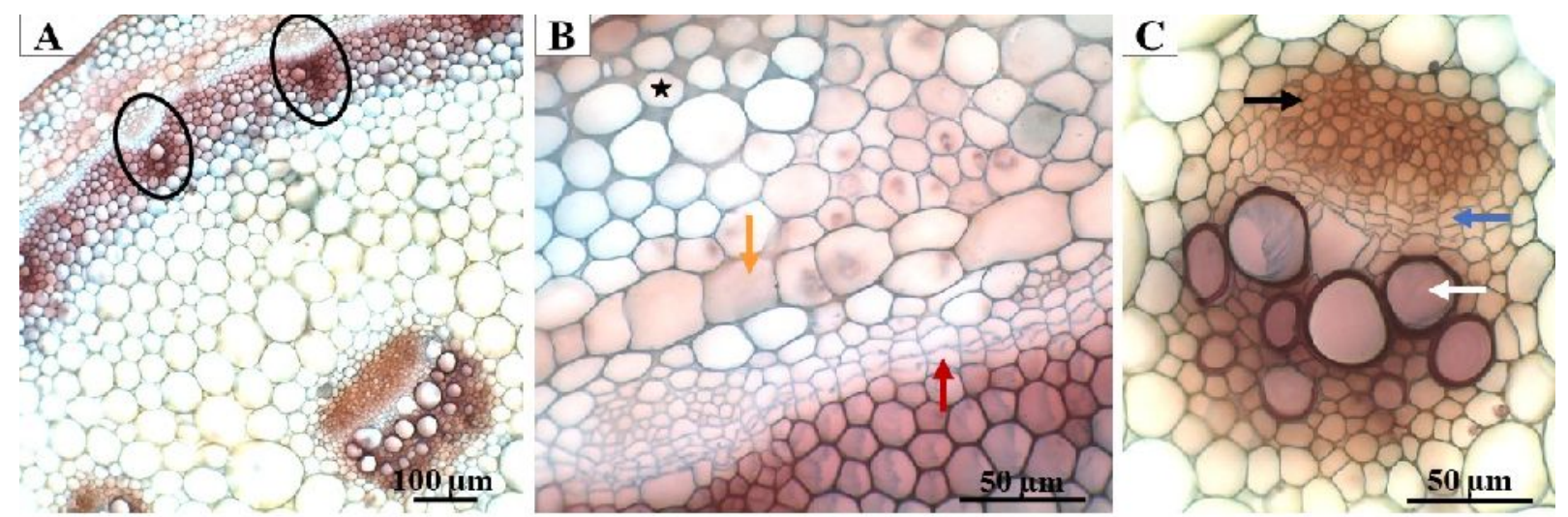

FIGURA 5. Secções transversais do caule. A. Vista geral evidenciando pequenos feixes vasculares em forma de cordão e feixes vasculares dispersos na região central do órgão (círculos). B. Colênquima angular (estrela), Bainha amilífera (seta amarela), Câmbio realizando mitose (seta vermelha). C. Detalhe do feixe medular colateral. Seta preta: Floema; seta azul: Câmbio; seta branca: Metaxilema. Fonte: Leticia Elias. 
Embora a presença de feixes vasculares dispersos na medula seja uma característica anatômica das monocotiledôneas, algumas famílias de eudicotiledôneas também apresentam feixes medulares (WILSON, 1924). Segundo Carlquist (1970) o padrão de crescimento anômalo povêm da perda da atividade cambial normal durante a evolução das plantas para o hábito herbáceo. De fato, a maior parte dos grupos dentro da ordem Caryophyllales que apresentam crescimento anômalo possuem hábito herbáceo (WILSON, 1924; RAJPUT; RAO, 1998; RAJPUT et al., 2008).

Durante a evolução, diversos grupos de plantas sofreram diferentes modificações, sejam elas morfológicas, estruturais ou bioquímicas, permitindo com que pudessem se adaptar às condições ambientais (RAJPUT et al., 2008).

Em vista frontal, as folhas de $B$. diffusa exibem células epidérmicas com parede anticlinal sinuosa (figuras $6 \mathrm{~A}, 6 \mathrm{C}$ ). As células epidérmicas possuem formatos variados quando relacionadas a outras espécies do gênero. Fadeyi et al. (1989) observaram que as paredes celulares são retas em Boerhavia repens L. e Boerhavia coccinea Mill. e curvas em Boerhavia erecta L., sendo a sinuosidade observada somente em $B$. diffusa.

A folha é anfihipoestomática com estômatos anomocíticos, corroborando com o trabalho de Fadeyi et al. (1989) e diferindo dos resultados observados por Patil et al. (2016). Os estômatos são encontrados nas partes aéreas, mais comumente em folhas, podendo ser encontrados em pecíolos e caules jovens (ESAU, 1976), sendo responsáveis pelas trocas gasosas e consequentemente pela perda de água por transpiração.

$\mathrm{Na}$ face adaxial foram observados tricomas glandulares bem como tricomas tectores pluricelulares (figuras 6A, 6B) e na face abaxial, cristais do tipo ráfides, além dos triomas glandulares (figura 6D).

Os tricomas são anexos epidérmicos com formas e funções variáveis e são muito utilizados na identificação de vegetais com potenciais farmacológicos (OLIVEIRA; AKISSUE, 2009). Ainda de acordo com os autores, os tricomas tectores desempenham função protetora, evitando o excesso de transpiração, além de estarem relacionados com a defesa vegetal. A presença de tricomas em Boerhavia também foi relatada em trabalhos anteriores (FADEYI et al., 1989; STRUWIG et al., 2011; PATIL et al., 2016). 

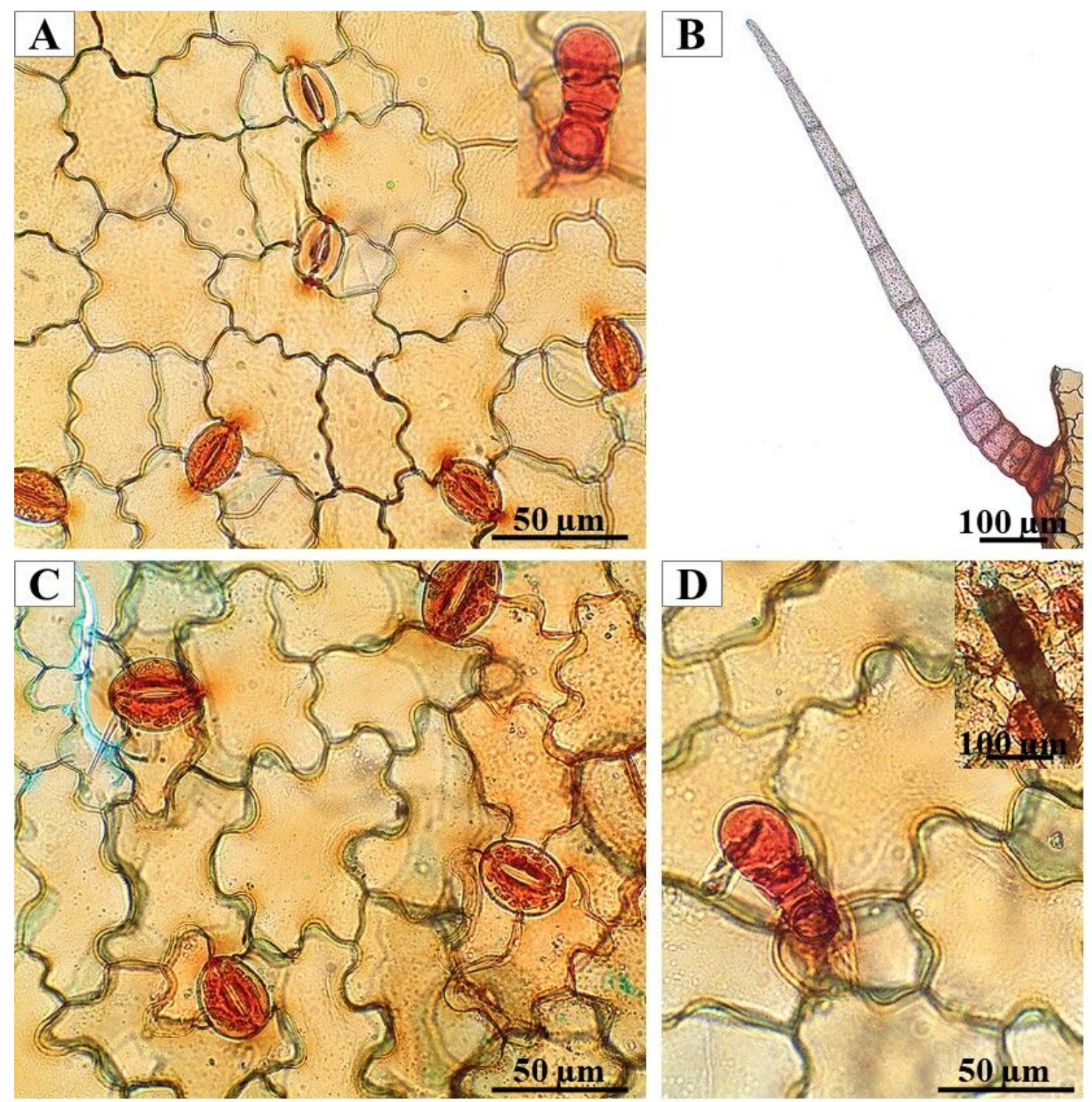

FIGURA 6. Secções paradérmicas das folhas de Boerhavia diffusa. A - B. Face Adaxial. A. Células com paredes celulares sinuosas, estômatos anomocíticos e em detalhe tricoma glandular. B. Tricoma tector pluricelular. C - D. Face Abaxial. C. Células com paredes celulares sinuosas e estômatos anomocíticos. D. Tricoma glandular e em detalhe cristais do tipo ráfides. Fonte: Leticia Elias.

Em secção transversal, o limbo foliar apresenta epiderme uniestratificada, com células isodiamétricas (figura 7A) revestidas por cutícula delgada. O mesofilo é dorsiventral e apresenta parênquima paliçadico constituído por um a dois estratos celulares, sendo o subepidérmico mais alongado e o estrato menor próximo aos feixes vasculares, enquanto que o parênquima lacunoso é constituído por cerca de três a quatro camadas (figura 7A). Os feixes vasculares encontram-se distribuidos pelo parênquima paliçadico e (figura 7A) são envoltos por uma bainha, denominada bainha do feixe (figuras 7A, 7B), onde ocorrem grãos de amido evidenciados pela marcação do teste histoquímico com lugol (tabela 1). No mesofilo também ocorrem idiobastos com cristais de oxalato de cálcio do tipo ráfides (figura $7 \mathrm{C}$ ) espalhados por toda extensão do limbo foliar. 

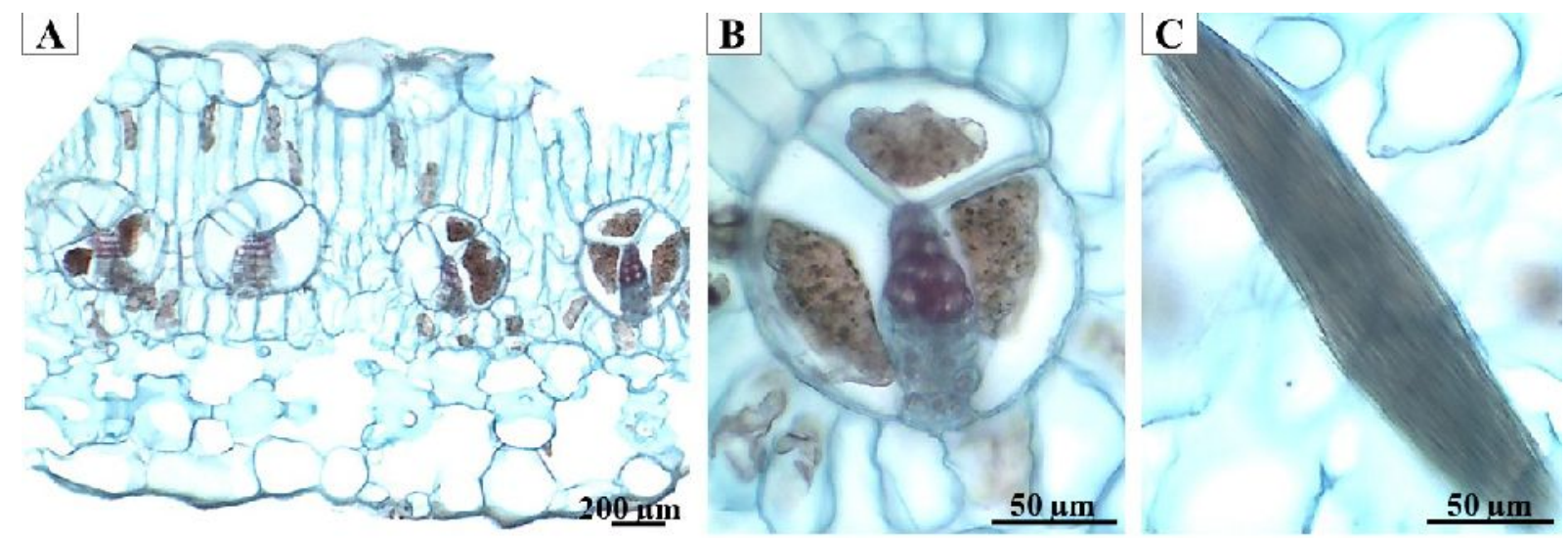

FIGURA 7. Secções transversais das folhas de Boerhavia diffusa. A. Vista geral mostrando o mesofilo dorsiventral com os feixes vasculares envoltos pela bainha do feixe. B. Detalhe da bainha do feixe. C. Idioblastos com cristais de oxalato de cálcio do tipo ráfides. Fonte: Leticia Elias.

Embora a espécie possua bainha do feixe ao redor dos elementos vasculares, característica mais comum em plantas com metabolismo fotossintético $\mathrm{C}_{4}$, ela possui metabolismo $\mathrm{C}_{3}$ (AJAO et al., 2017). Os autores examinaram aspectos foliares como índice e densidade estomática, tamanho dos estômatos e a distância entre eles, espessura foliar, espessura do mesofilo, densidade e distância das veias, distância interveolar, espaços aéreos intercelulares e tecido Kranz, e chegaram a concusão que Boerhavia erecta, $B$. coccinea e $B$. repens são plantas com metabolismo $C_{4}$ e $B$. Diffusa, a única dentre elas, com metabolismo $\mathrm{C}_{3}$.

Nas plantas com metabolismo $\mathrm{C}_{3}$ as células da bainha do feixe não são especializadas e geralmente possuem poucas ou nenhuma organela. Contrastando com muitas plantas $\mathrm{C}_{3}$, todas as intermediárias para o metabolismo fotossistético $\mathrm{C}_{4}$ possuem a bainha evidente, com presença de cloroplastos em suas células (MONSON et al., 1984). A anatomia foliar observada em B. diffusa mostra grande discrepância se comparado com a anatomia de outras plantas com metabolismo fotossintético $\mathrm{C}_{3}$, podendo ser um indicativo de que a espécie pode estar evoluindo para 0 metabolismo $\mathrm{C}_{4}$, levando em consideração que outras espécies do gênero utilizam essa via fotossintética.

\section{CONCLUSÃO}

Anatomicamente, pode-se concluir que raízes e caules apresentam padrão de crescimento anômalo, característica comum para o gênero e para a ordem Caryophyllales.

Com relação aos aspectos morfológicos de $B$. diffusa, o formato cordiforme e a base cordada da folha são caracteres distintivos entre as demais espécies do gênero.

A parede celular sinuosa das células epidérmicas e presença da bainha do feixe são caracteres anatômicos foliares que juntamente com os caracteres morfológicos acima auxiliam na identificação da espécie.

Os testes histoquímicos destacaram a presença de amido, lignina e lipídeo, que além de servir como fonte energética (amido), são substâncias que podem auxiliar à resistência do vegetal no ambiente. 


\section{REFERÊNCIAS}

AJAO, A. A.; JIMOH, M. A.; SAHEED, S. A. Studies on anatomical characters indicating $\mathrm{C}_{3}$ and $\mathrm{C}_{4}$ photosynthetic metabolism in the genus Boerhavia L. (Nyctaginaceae). Taiwania, v. 62, n. 3, p. 265 271, 2017. Disponível em: <http://tai2.ntu.edu.tw/taiwania/abstract.php?type=abstract\&id=1510 >. $\quad$ doi: 10.6165/tai.2017.62.265

BAAS, P. The wood anatomical range in Ilex (Aquifoliaceae) and its ecological and phylogenetic significance. Blumea, v. 21, n. 2, p. 193-260, 1973. Disponível em: < http://www.repository.naturalis.nl/document/565651>.

BABU, K.; PRIYA DHARISHINI, M.; AUSTIN, A. Comparative root anatomy and thin layer chromatographic identification of Boerhavia diffusa $\mathrm{L}$. and Boerhavia erecta $\mathrm{L}$. The Journal of Phytopharmacology, v. 6, n. 6, p. 318-321, 2017. Disponível em: $<$ http://www.phytopharmajournal.com/Vol6_Issue6_02.pdf>.

BELL, A. D. Plant form: an illustrated guide to flowering plant morphology. Timber Press: Portland. 2008. $431 \mathrm{p}$.

BRANDELLI, C. L. C. Plantas Medicinais: histórico e conceitos. in: MONTEIRO, S. C.; BRANDELLI, C. L. C. Farmacobotânica: aspectos teóricos e aplicação. Porto Alegre: Artmed, 2017, p. 1-13.

CARLQUIST, S. Wood anatomy of insular species of Plantago and the problem of raylessness. Bulletin of The Torrey Botanical Club, v. 97, n. 6, p. 353-361, 1970. Disponível em: <https://www.jstor.org/stable/2483855 >. doi: 10.2307/2483855

ELLIS, B.; DALY D. C.; HICKEY, L. J.; JOHNSON, K. R.; MITCHELL J. D. et al. Manual of leaf architecture. Ithaca: Cornell University Press, 2009. 190p.

ESAU, K. Anatomia das plantas com sementes. 1. ed. São Paulo: Edgard Blucher, 1976. 293p.

FADEYI, M. 0.; ADEOYE, A. 0.; OLOWOKUDEJO, J. D. Epidermal and Phytochemical Studies in the Genus Boerhavia (Nyctaginaceae) in Nigeria. International Journal of Crude Drug Research, v. 27, n. 3, p. 178-184, 1989. Disponível em: <https://doi.org/10.3109/13880208909053960>. doi: $10.3109 / 13880208909053960$

FIGUEIREDO, A. C. S.; BARROSO, J. M. G.; PEDRO, L. M. G.; ASCENSÃO, L. Histoquímica e citoquímica em plantas: princípios e protocolos. 1. ed. Lisboa: Faculdade de Ciências da Universidade de Lisboa, Centro de Biotecnologia Vegetal, 2007. 80p.

GRANDI, T. S. M. Tratado das plantas medicinais: mineiras, nativas e cultivadas. 1. ed. Belo Horizonte: Adaequatio Estúdio. 2014. 1204p.

GUERRA, A.; SCREMIN-DIAS, E. Leaf traits, sclerophylly and growth habitats in plant species of a semiarid environment. Brazilian Journal of Botany, v. 41, n. 1, p. 
131-144, 2017. Disponível em: <https://link.springer.com/article/10.1007/s40415-0170416-x>. doi: 10.1007/s40415-017-0416-x

JOHANSEN, D. A. Plant microtechnique. 1. ed. New York: McGraw-Hill Company, 1940. 523p.

LOEHLE, C. Anomalous Responses of Plants to $\mathrm{CO}_{2}$ Enrichment. Oikos, v. 73, p. 181-187, 1995. Disponível em: <https://www.jstor.org/stable/3545906>. doi: $10.2307 / 3545906$

LORENZI, H.; MATOS, F. J. A. Plantas medicinais no Brasil: nativas e exóticas. 2. ed. Nova Odessa, SP: Instituto Plantarum, 2008. 544p.

LUQUE, R.; SOUZA, C. H.; KRAUS, E. J. Métodos de coloração de Roeser (1972) modificado e Kropp (1972) visando a substituição do azul de astra pelo azul de alcião 8GS ou 8GX. Acta Botanica Brasílica, v.10, n.2, p.199-212, 1996. Disponível em: <http://dx.doi.org/10.1590/S0102-33061996000200001>. doi: 10.1590/S010233061996000200001

MESSIAS, M. C. T. B.; MENEGATTO, M. F.; PRADO, A. C. C.; SANTOS B. R.; GUIMARÃES, M. F. M. Uso popular de plantas medicinais e perfil socioeconômico dos usuários: um estudo em área urbana em Ouro Preto, MG, Brasil. Revista Brasileira de Plantas Medicinais, v. 17, n. 1, p. 16-104, 2015. Disponível em: <http://dx.doi.org/10.1590/1983-084X/12_139>. doi: 10.1590/1983-084X/12_139

MILLER, L. Microtecnica e fotomicrografia. Piracicaba, Escola Superior de Agricultura "Luiz de Queiroz", 1968. n.p. (Apostila de Curso).

MISHRA, S.; AERI, V.; GAUR, P. K.; JACHAK, S. M. Phytochemical, Therapeutic, and Ethnopharmacological Overview for a Traditionally Important Herb: Boerhavia diffusa Linn. BioMed Research International, v. 24, p. 1-19, 2014. Disponível em: <http://dx.doi.org/10.1155/2014/808302>. doi: 10.1155/2014/808302

MONSON, R. K.; EDWARDS, G. E.; KU, M. S. B. $\mathrm{C}_{3}-\mathrm{C}_{4}$ Intermediate Photosynthesis in Plants. BioScience, v. 34, n. 9, p. 563-574, 1984. Disponível em: <https://doi.org/10.2307/1309599>. doi: 10.2307/1309599

NANDI, R.; GHOSH, R. Phytochemical and Biological Importance of Boerhavia diffusa: A Plant of Ethnopharmacological knowledge. International Journal of Pharma Sciences and Research (IJPSR), v. 7, n. 3, p. 134-143, 2016. Disponível em: <http://www.ijpsr.info/docs/lJPSR16-07-03-001.pdf>.

OLIVEIRA, F.; AKISUE, G. Fundamentos de farmacobotânica e de morfologia vegetal. 3. ed. São Paulo: Atheneu, 2009. 228p.

PATIL, V. S.; RAJPUT, K. S.; MALPATHAK, N. P. Comparative study on morphoanatomy of leaf, stem and root of Boerhaavia diffusa L. (Nyctaginaceae) and its adulterant plants. Brazilian Journal of Pharmaceutical Sciences, v. 52, n. 3, p. 
433-442, 2016. Disponível em: <http://dx.doi.org/10.1590/S198482502016000300009>. doi: 10.1590/S1984-82502016000300009

PEARSE, A. G. E. Histochemistry: theoretical and applied. 3. ed. Baltimore: Williams \& Wilkins, 1972. 758p.

PRAMANICK, D. D.; MAITI, G. G. Foliar anatomical study of Boerhavia diffusa L.: a potent medicinal plant. Annals of Plant Sciences, v. 6, n. 4, p. 1598-1601, 2017. Disponível em: <http://dx.doi.org/10.21746/aps.2017.04.001>. doi: 10.21746/aps.2017.04.001

PURVIS, M. J.; COLLIER, D. C.; WALLS, D. Laboratory techniques in botany. London: Butterworths, 1964. 371p.

RAJPUT, K. S.; PATIL, V. S.; SHAH, D. G. Formation of successive cambia and stem anatomy of Sesuvium sesuvioides (Aizoaceae). Botanical Journal of the Linnean Society, v. 158, n. 3, p. 548-555, 2008. Disponível em: <https://doi.org/10.1111/j.1095-8339.2008.00867.x>. doi: 10.1111/j.10958339.2008.00867.x

RAJPUT, K. S.; RAO, K. S. Cambial anatomy and absence of rays in the stem of Boerhaavia species (Nyctaginaceae). Annales botanici Fennici, v. 35, n. 2, p. 131135, $1998 . \quad$ Disponível em: $<$ https://www.researchgate.net/publication/236853892_Cambial_anatomy_and_abse nce_of_rays_in_the_stem_of_Boerhaavia_species_Nyctaginaceae $>$.

SALIBA, E. O. S.; RODRIGUEZ, N. M.; MORAIS, S. A. L.; PILÓ-VELOSO, D. Ligninas - métodos de obtenção e caracterização química. Ciência Rural, v. 31, n. 5, p. 917-928, 2001. Disponível em: <http://www.scielo.br/pdf/\%0D/cr/v31n5/a31v31n5.pdf>.

SILVA, A. F.; SANTOS, A. P.; RABELO, M. F. R. Identificação botânica das plantas medicinais. Informe Agropecuário, v. 31, n. 255, 2010. Disponível em: $<$ https://www.researchgate.net/publication/236322610_Identificacao_botanica_das_p lantas_medicinais>.

STRUWIG, M.; JORDAAN, A.; SIEBERT, S. J. Anatomy of the Southern African Boerhavia and Commicarpus species (Nyctaginaceae). Bangladesh Journal of Plant Taxonomy, v. 18, n. 2, p. 105-115, 2011. Disponível em: <http://dx.doi.org/10.3329/bjpt.v18i2.9297>. doi: 10.3329/bjpt.v18i2.9297

VADIVEL, V.; BRINDHA, P. Phytochemical investigation for the authentication of Indian traditional herbal drug Boerhavia diffusa and its differentiation from morphologically similar plant $B$. erecta. International Journal of Pharmaceutical Chemistry, v. 7, n. 6, p. 86-94, 2017. Disponível em: <https://doi.org/10.7439/ijpc>. doi: $10.7439 /$ ijpc

WAECHTER J. L. Aspectos ecológicos da vegetação de restinga no Rio Grande do Sul, Brasil. Comunicações do Museu de Ciências da PUCRS, Série Botânica, n. 
33,

p. 49-68,

1985.

Disponível

em:

<http://www.scielo.br/scielo.php?script=sci_nlinks\&ref=000421\&pid=S0102-

$3306200600010000800056 \& \operatorname{lng}=$ en $>$.

WAJID, M.; JABEEN, S.; ASLAM, M. S.; AHMAD, M. S. An Update Review on Ethnomedicinal, Phytochemical and Pharmacological Profile of genus Boerhavia. International Journal of Complementary \& Alternative Medicine, v. 6, n. 3, 2017. Disponível em: <https://medcraveonline.com/IJCAM/IJCAM-06-00189.php>. doi: 10.15406/ijcam.2017.06.00189

WILSON, C. L. Medullary Bundle in Relation to Primary Vascular System in Chenopodiaceae and Amaranthaceae. Botanical Gazette, v. 78, n. 2, p. 175-199, 1924. Disponível em: <https://www.jstor.org/stable/2469882>.

ZENI, A. L. B.; PARISOTTO, A. V.; MATTOS, G.; HELENA, E. T. S. Utilização de plantas medicinais como remédio caseiro na Atenção Primária em Blumenau, Santa Catarina, Brasil. Ciência \& Saúde Coletiva, v. 22, n. 8, p. 2703-2712, 2017. Disponível em: <http://dx.doi.org/10.1590/1413-81232017228.18892015>. doi: 10.1590/1413-81232017228.18892015 